\title{
Investigation of Ion Beam Extraction Mechanism for Higher Thrust Density of Ion Thrusters
}

\author{
By Kenta HIRAMOTO ${ }^{1)}$ and Yoshinori TAKAO ${ }^{2)}$ \\ 1) Department of Systems Integration, Yokohama National University, Yokohama, Japan \\ ${ }^{2)}$ Division of Systems Research, Yokohama National University, Yokohama, Japan
}

(Received July 30th, 2015)

\begin{abstract}
We have investigated ion beam extraction mechanism using two dimensional axisymmetric particle-in-cell simulations with Monte Carlo collisions (PIC/MCC) under various conditions of grid structures. The calculations are carried out for both the plasma region and the vacuum region simultaneously, where the former is $5.0 \mathrm{~mm}$ in radius and $10 \mathrm{~mm}$ in length and the latter is $6.0 \mathrm{~mm}$ in radius and $20 \mathrm{~mm}$ in length. The PIC/MCC results have shown that the ion beam current is affected by the gap distance of the grids and thickness of the screen grid, but is not affected by the hole diameter of the screen grid. Moreover, the optimum value of the difference between the hole diameter of the screen grid and that of the accelerator grid is $1.4 \mathrm{~mm}$ at various grid gap distances and thicknesses under the following conditions: the gas pressure is $3.2 \mathrm{mTorr}$, the absorbed power is $500 \mathrm{~mW}$ and the beam voltage is $1100 \mathrm{~V}$.
\end{abstract}

Key Words: Ion Thrusters, PIC/MCC, Ion Beam Extraction

\section{Nomenclature}

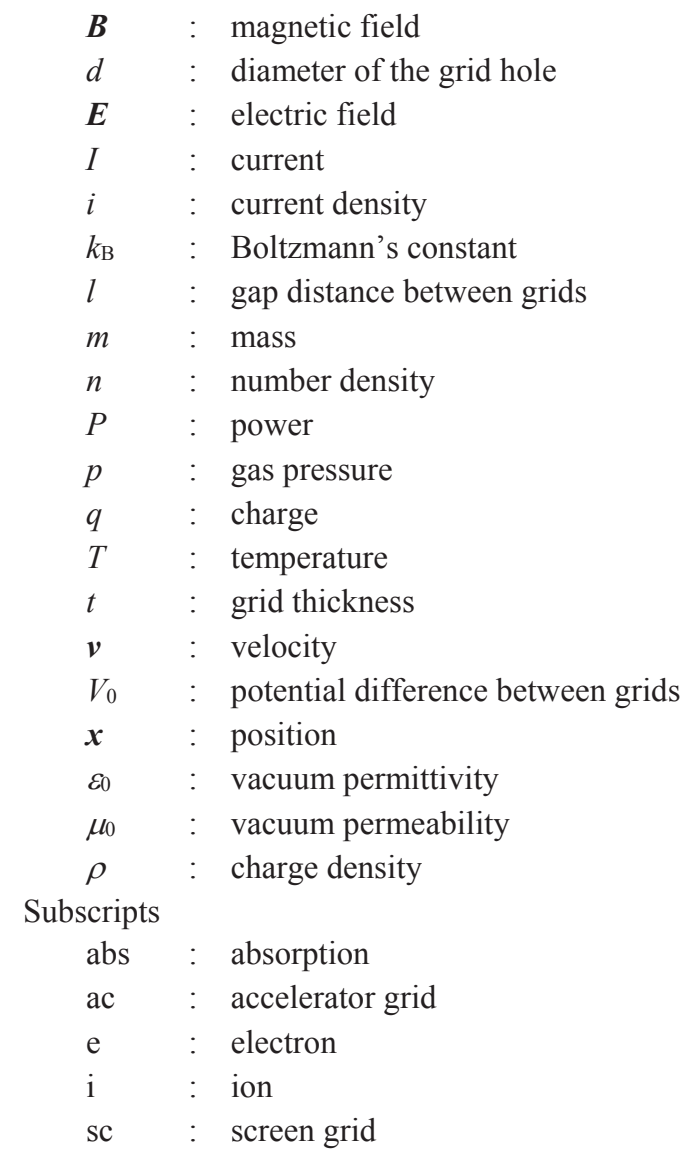

\section{Introduction}

Recently, miniaturization of satellites has been very popular. It makes possible to decrease mission costs and development period, and thus even small companies and universities can launch and operate microsatellites. However, microsatellites have limits of weight, volume, and power, which requires that thrusters mounted on them must be small. ${ }^{1)}$ One of such thrusters can be ion thrusters. For example, a 50 kg-class satellite, HODOYOSHI-4, was developed by the University of Tokyo and the Next Generation Space Technology Research Association (NESTRA) in Japan, and launched in 2014. The satellite mounted a miniature ion propulsion system (MIPS), ${ }^{2)}$ and the MIPS was already operated in space.

Ion thrusters have high specific impulse and efficiency, while the thrust density is very low, which requires long-term operation for acceleration. If ion thrusters provided higher thrust density, their applications would be expanded. NASA GRC already started working on the development of high-thrust density ion engines for high power applications in collaboration with the Aerospace Corporation, and the University of Michigan. ${ }^{3,4)}$ Although they focus on the application to high-power primary propulsion, the technology would also be applicable to micropropulsion. In our early studies, we developed a two-dimensional particle model for a micro RF ion thruster and investigated the plasma parameters and ion beam profiles. ${ }^{5)}$ In this model, the plasma generation and the ion beam acceleration can be analyzed simultaneously. Since the ion beam extraction is dependent on the characteristics of the plasma source as well as the grid structure, it is better to analyze the plasma generation and the ion beam acceleration continuously. In this study ion beam 
extraction mechanism has been investigated using this particle model to find the best condition of the beam extraction for higher thrust density.

\section{Numerical Model}

\subsection{Configuration}

In this analysis, we have conducted two-dimensional particle-in-cell simulations with Monte Carlo collisions (PIC/MCC). Figure 1 shows our calculation model. The plasma region, which is enclosed by a $1-\mathrm{mm}$-thick dielectric cylinder with a five-turn coil, is $5.0 \mathrm{~mm}$ in radius and $10 \mathrm{~mm}$ in length. The ion accelerator system consists of screen and accelerator grids, and the vacuum region, where ion beam is extracted, is $6.0 \mathrm{~mm}$ in radius and $20 \mathrm{~mm}$ in length. In addition, a ground electrode is positioned $1 \mathrm{~mm}$ downstream of the accelerator grid. Since the calculation is carried out for both the plasma region and the vacuum region simultaneously, no assumptions are required for the ion beam extraction, that is, the plasma density and the electron temperature in the ion source can be obtained self-consistently.

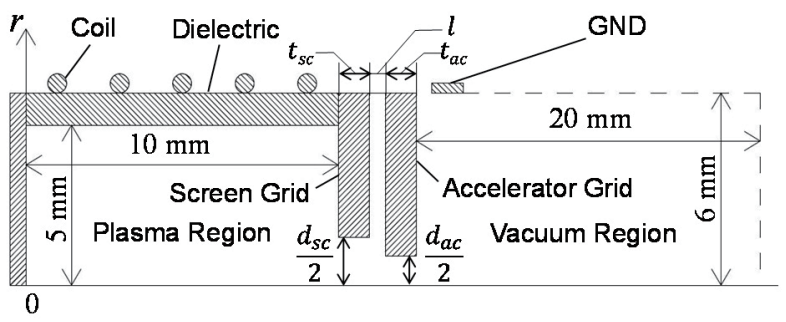

Fig. 1. Calculation model.

\subsection{Assumptions}

We have investigated under the following assumptions.

i). Only electron and singly-ionized $\mathrm{Xe}^{+}$are treated as particles.

ii). Neutral particles are spatially and temporally uniform with a Maxwellian distribution at a gas temperature of $300 \mathrm{~K}$ in the plasma region, while there are no collisions downstream of the accelerator grid.

iii). The reactions between charged particles and neutrals are elastic, excitation, and ionization collision for electrons ${ }^{6-8)}$, and elastic and charge exchange collisions for ions. ${ }^{9)}$

$$
\begin{array}{ll}
\mathrm{e}+\mathrm{Xe} \rightarrow \mathrm{e}+\mathrm{Xe} & \text { (Elastic collision). } \\
\mathrm{e}+\mathrm{Xe} \rightarrow \mathrm{e}+\mathrm{Xe}^{*} & \text { (Excitation). } \\
\mathrm{e}+\mathrm{Xe} \rightarrow \mathrm{e}+\mathrm{Xe}^{+}+\mathrm{e} & \text { (Ionization). } \\
\mathrm{Xe}^{+}+\mathrm{Xe} \rightarrow \mathrm{Xe}^{+}+\mathrm{Xe} & \text { (Elastic collision). } \\
\mathrm{Xe}^{+}+\mathrm{Xe} \rightarrow \mathrm{Xe}+\mathrm{Xe}^{+} & \text {(Charge exchange) }
\end{array}
$$

\subsection{Motion and collisions of charged particles}

The equation of motion for charged particles is described by

$$
\begin{gathered}
\frac{d \boldsymbol{v}}{d t}=\frac{q}{m}(\boldsymbol{E}+\boldsymbol{v} \times \boldsymbol{B}), \\
\frac{d \boldsymbol{x}}{d t}=\boldsymbol{v} .
\end{gathered}
$$

Eqs. (1) and (2) are solved by leap-frog method and Buneman-Boris method. ${ }^{10)}$ In this study, we assume axisymmetric model, so that the position advance of particles closed to axis poses singular problems. To avoid these problems, we employ a coordinate rotation for the position advance. ${ }^{10)}$ We also employ the null-collision method in MCC with cross sections for electrons and ions, to reduce calculation time. ${ }^{11)}$

\subsection{Electric field}

The electrostatic field $\boldsymbol{E}$ and the potential $\phi$ are given by

$$
\begin{gathered}
\boldsymbol{E}=-\nabla \phi, \\
\left(\frac{\partial^{2}}{\partial r^{2}}+\frac{1}{r} \frac{\partial}{\partial r}+\frac{\partial^{2}}{\partial z^{2}}\right) \phi=-\frac{\rho(r, z)}{\varepsilon_{0}} .
\end{gathered}
$$

Eq. (4) is solved by using the method of successive-over-relaxation (SOR) method. The boundary conditions of $\phi$ are zero radial potential gradient on the $z$ axis $(\partial \phi / \partial r=0$ at $r=0)$ due to the axisymmetry, and zero potential at all the walls. Here, to eliminate an axisymmetric error of charge density on the $z$ axis, we employ a symmetric spline weighting presented by Verboncoeur. ${ }^{12)}$ In addition, to decrease a numerical noise, we apply a digital smoothing algorithm to the space charge. ${ }^{13)}$

\subsection{Electromagnetic field}

In our model, we assume that the coil is composed of five concentric rings, so that the electric field by the coil has only $\theta$-directional component. All quantities, such as electric field and current density, are also assumed harmonic oscillation depending on time. Thus, $\theta$-directional components of the electric field $E_{\theta}$ and the plasma current density $i_{\theta}$ are described as

$$
\begin{aligned}
E_{\theta} & =\widetilde{E}_{\theta} e^{j \omega t}, \\
i_{\theta} & =\widetilde{I}_{\theta} e^{j \omega t},
\end{aligned}
$$

where $j$ is the imaginary unit, $\omega$ is the RF angular frequency, $\tilde{E}_{\theta}$ and $\tilde{I}_{\theta}$ are the complex amplitude, which satisfy the following equation: ${ }^{14)}$

$$
\left(\frac{\partial^{2}}{\partial r^{2}}+\frac{1}{r} \frac{\partial}{\partial r}+\varepsilon_{0} \mu_{0} \omega^{2}-\frac{1}{r^{2}}+\frac{\partial^{2}}{\partial z^{2}}\right) \widetilde{E}_{\theta}=j \omega \mu_{0} \widetilde{I}_{\theta} .
$$

The boundary conditions are $\tilde{E}_{\theta}=0$ at the metal walls and on the $z$ axis $(r=0)$. The electric field on the plasma-dielectric window interfaces is analytically derived from Biot-Savart's law, and the magnetic field $\boldsymbol{B}$ is given by Faraday's law:

$$
\nabla \times \boldsymbol{E}=-\frac{\partial \boldsymbol{B}}{\partial t} .
$$

\subsection{Equations for evaluation}

Generally, the ion beam current density is evaluated by Child-Langmuir law:

$$
i_{\mathrm{CL}}=\frac{4 \varepsilon_{0}}{9} \sqrt{\frac{2 e}{m_{\mathrm{i}}}} \frac{V_{0}^{3 / 2}}{l_{\mathrm{e}}^{2}},
$$

where $l_{\mathrm{e}}$ is the effective gap distance of grids given by ${ }^{15)}$

$$
l_{\mathrm{e}}=\sqrt{\left(l+t_{\mathrm{sc}}\right)^{2}+\frac{d_{\mathrm{sc}}^{2}}{4}} .
$$

Although the Child-Langmuir law depends on grid structure, it does not consider the plasma parameters, such as the plasma 
density and the electron temperature. In this study, we have also compared the calculated current with the ion saturation current density:

$$
i_{\mathrm{pi}}=q n_{\mathrm{p}} \sqrt{\frac{k_{B} T_{\mathrm{e}}}{m_{\mathrm{i}}}} \exp \left(-\frac{1}{2}\right),
$$

where $n_{\mathrm{p}}$ is a bulk plasma density.

\section{Results and Discussion}

\subsection{Dependence on the gap distance between grids}

Figure 2 shows the dependence on the gap distance between screen and accelerator grids. The other conditions are as follows: $p=3.2 \mathrm{mTorr}, P_{\mathrm{abs}}=500 \mathrm{~mW}, V_{0}=1100 \mathrm{~V}\left(V_{\mathrm{sc}}=\right.$ $1000 \mathrm{~V}$ and $\left.V_{\mathrm{ac}}=-100 \mathrm{~V}\right), t_{\mathrm{sc}}=0.3 \mathrm{~mm}, t_{\mathrm{ac}}=0.3 \mathrm{~mm}, d_{\mathrm{sc}}=$ $3.2 \mathrm{~mm}$, and $d_{\mathrm{ac}}=1.8 \mathrm{~mm}$. In this case, the calculated beam current $I_{\mathrm{b}}$ has decreased with increasing the gap distance. Here, $I_{\mathrm{b}}$ is obtained by subtracting the accelerator current $I_{\text {ac }}$ from the screen current $I_{\mathrm{sc}}$. The gradient of the calculated current agrees with that of the Child-Langmuir law current $I_{\mathrm{CL}}$, so that it is appropriate to include the gap distance $l$ in the effective gap distance $l_{\mathrm{e}}$ given by Eq. (10). Note that ion saturation current $I_{\mathrm{pi}}$ is independent of the gap discance $l$ because the plasma density is a function of $P_{\text {abs, }}$ which is fixed in this case.

\subsection{Dependence on the grids thickness}

Figure 3 shows the dependence on the screen grid thickness. The other conditions are as follows: $p=3.2$ mTorr, $P_{\text {abs }}=500$ $\mathrm{mW}, V_{0}=1100 \mathrm{~V}, l=0.8 \mathrm{~mm}, t_{\mathrm{ac}}=0.3 \mathrm{~mm}, d_{\mathrm{sc}}=3.2 \mathrm{~mm}$, and $d_{\mathrm{ac}}=1.8 \mathrm{~mm}$. In this case, with increasing the screen grid thickness, the calculated beam current $I_{\mathrm{b}}$ has decreased and the gradient of $I_{\mathrm{b}}$ agrees with that of $I_{\mathrm{CL}}$.

Figure 4 shows the dependence on the accelerator grid thickness. The other conditions are as follows: $p=3.2$ mTorr, $P_{\mathrm{abs}}=500 \mathrm{~mW}, V_{0}=1100 \mathrm{~V}, l=0.8 \mathrm{~mm}, t_{\mathrm{sc}}=0.3 \mathrm{~mm}, d_{\mathrm{sc}}=$ $3.2 \mathrm{~mm}$, and $d_{\mathrm{ac}}=1.8 \mathrm{~mm}$. As shown in Fig. 4 , it is found that the accelerator grid thickness does not affect the beam current.

From Figs. 3 and 4, it is reasonable to include the screen grid thickness and not to include the accelerator grid thickness in the effective gap distance $l_{\mathrm{e}}$.

\subsection{Dependence on the diameters of grids hole}

Figure 5 shows the dependence on the hole diameter of the screen grid. The other conditions are as follows: $p=3.2 \mathrm{mTorr}$, $P_{\mathrm{abs}}=500 \mathrm{~mW}, V_{0}=1100 \mathrm{~V}, l=0.8 \mathrm{~mm}, t_{\mathrm{sc}}=0.3 \mathrm{~mm}, t_{\mathrm{ac}}=$ $0.3 \mathrm{~mm}$, and $d_{\mathrm{ac}}=1.8 \mathrm{~mm}$. In this case, the calculated beam current density $i_{\mathrm{b}}$ has become constant below $d_{\mathrm{sc}}=3.2 \mathrm{~mm}$ while the Child-Langmuir law current density $i_{\mathrm{CL}}$ increases with decreasing $d_{\text {sc. Table }} 1$ summarizes each current densities under the conditions. It seems that the tendency above $d_{\mathrm{sc}}=$ $3.2 \mathrm{~mm}$ agrees with the Child-Langmuir law. However, it is due to the increase of the accelerator grid current, where some of the ion beam has collided with the accelerator grid directly because of the increase in the difference between hole diameter of the screen grid and that of the accelerator grid. Hence, it would be inappropriate to include the hole diameter of the screen grid in the effective gap distance $l_{\mathrm{e}}$.

Figures 6 and 7 show the dependence on the hole diameters of accelerator grid at $d_{\mathrm{sc}}=3.2 \mathrm{~mm}$ and $d_{\mathrm{sc}}=3.4 \mathrm{~mm}$, respectively. The other conditions are as follows: $p=3.2$

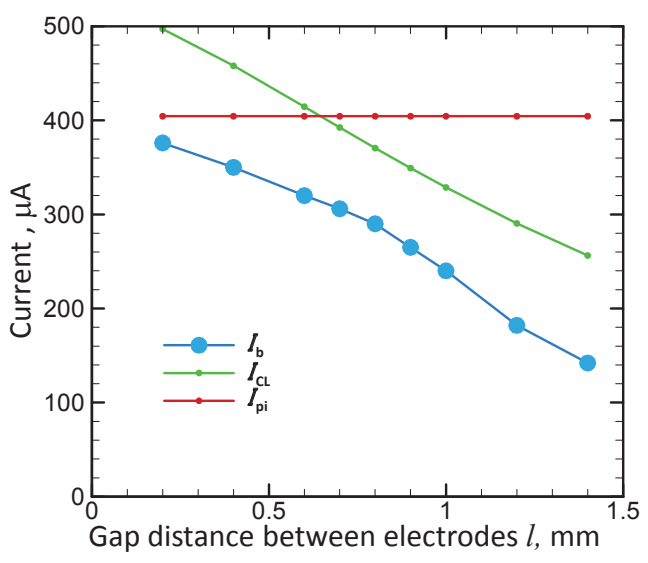

Fig. 2. Dependence on the gap distance between grids.

mTorr, $P_{\mathrm{abs}}=500 \mathrm{~mW}, V_{0}=1100 \mathrm{~V}, l=0.8 \mathrm{~mm}, t_{\mathrm{sc}}=0.3 \mathrm{~mm}$,

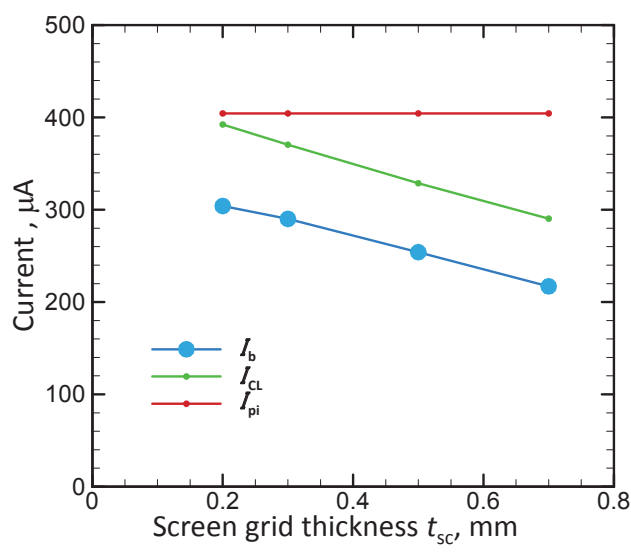

Fig. 3. Dependence on the screen grid thickness.

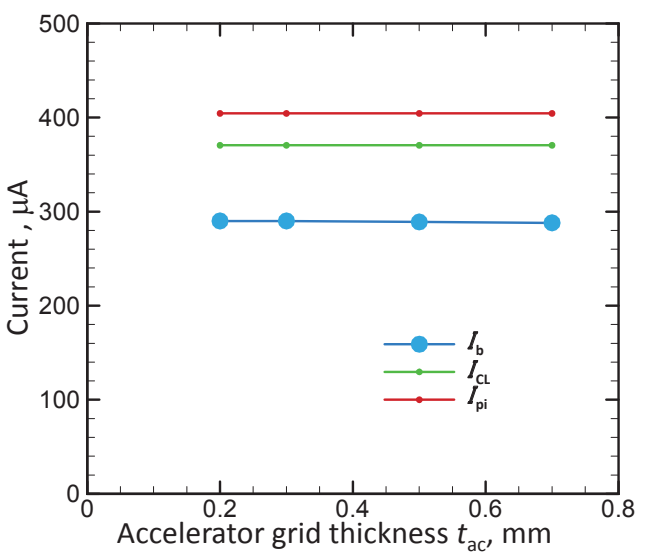

Fig. 4. Dependence on the accelerator grid thickness.

and $t_{\mathrm{ac}}=0.3 \mathrm{~mm}$. There are turning points, such as $d_{\mathrm{ac}}=1.8$ $\mathrm{mm}$ for Fig. 6 and $d_{\mathrm{ac}}=2.0 \mathrm{~mm}$ for Fig. 7. If the hole diameters of the accelerator grid are equal or greater than these values, the calculated current density $i_{\mathrm{b}}$ has become 


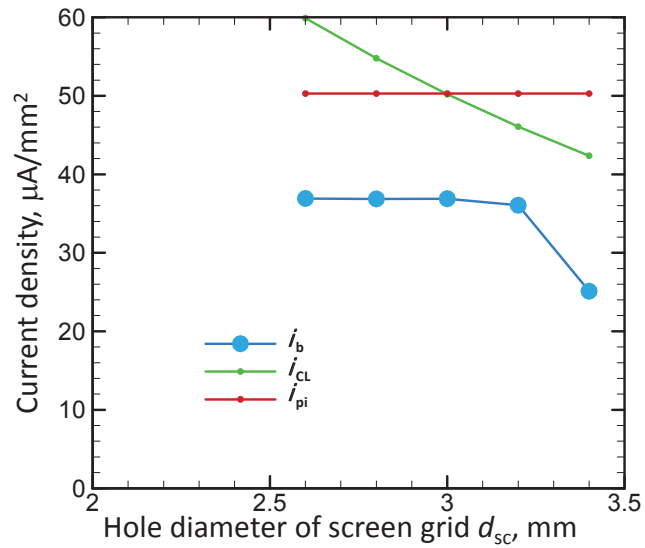

Fig. 5. Dependence on the hole diameter of the screen grid.

Table 1. Current densities for dependence on the hole diameter of the screen grid.

\begin{tabular}{|c|c|c|c|}
\hline$d_{\mathrm{sc}}(\mathrm{mm})$ & $i_{\mathrm{b}}\left(\mu \mathrm{A} / \mathrm{mm}^{2}\right)$ & $i_{\mathrm{sc}}\left(\mu \mathrm{A} / \mathrm{mm}^{2}\right)$ & $i_{\mathrm{ac}}\left(\mu \mathrm{A} / \mathrm{mm}^{2}\right)$ \\
\hline 3.4 & 25.1 & 38.3 & 13.2 \\
\hline 3.2 & 36.1 & 38.3 & 2.2 \\
\hline 3.0 & 36.9 & 38.0 & 1.1 \\
\hline 2.8 & 36.9 & 37.7 & 0.9 \\
\hline 2.6 & 36.9 & 37.5 & 0.7 \\
\hline
\end{tabular}

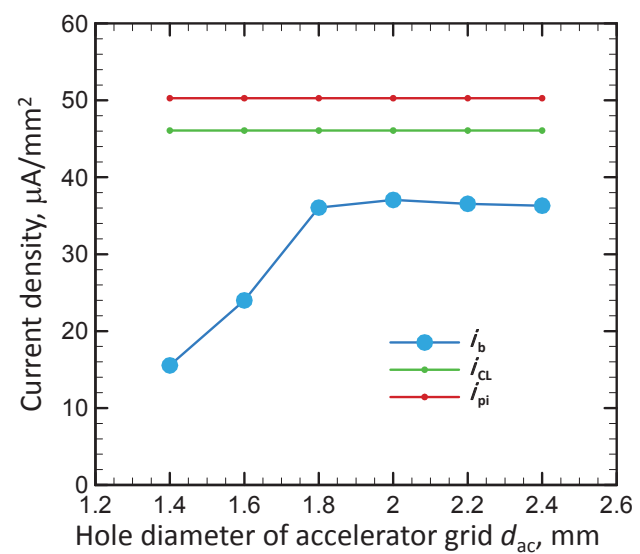

Fig. 6. Dependence on the hole diameter of the accelerator grid $\left(d_{\mathrm{sc}}=3.2 \mathrm{~mm}\right)$.

constant. This tendency agrees with the Child-Langmuir law. On the other hand, if the diameters are smaller than these values, the calculated current density $i_{\mathrm{b}}$ has decreased. Tables 2 and 3 summarizes each current densities under the conditions, $d_{\mathrm{sc}}=3.2 \mathrm{~mm}$ and $d_{\mathrm{sc}}=3.4 \mathrm{~mm}$, respectively. It is due to the same reason as the dependence on the hole diameter of the screen grid.

In Figs. 5-7, the calculated current densities $i_{\mathrm{b}}$ have decreased due to the increase in difference between hole

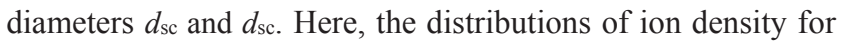
$d_{\mathrm{ac}}=1.4,1.8 \mathrm{~mm}$ at $d_{\mathrm{sc}}=3.2 \mathrm{~mm}$ are shown in Fig. 8. Comparing these figures, it is found that some of ion beam on

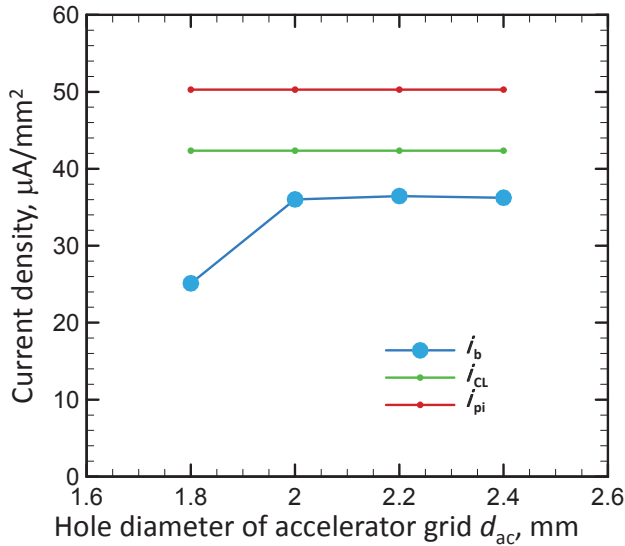

Fig. 7. Dependence on the hole diameter of the accelerator grid $\left(d_{\mathrm{sc}}=3.4 \mathrm{~mm}\right)$.

Table 2. Current densities for dependence on the diameter of the accelerator grid hole $\left(d_{\mathrm{sc}}=3.2 \mathrm{~mm}\right)$.

\begin{tabular}{|c|c|c|c|}
\hline$d_{\mathrm{ac}}(\mathrm{mm})$ & $i_{\mathrm{b}}\left(\mu \mathrm{A} / \mathrm{mm}^{2}\right)$ & $i_{\mathrm{sc}}\left(\mu \mathrm{A} / \mathrm{mm}^{2}\right)$ & $i_{\mathrm{ac}}\left(\mu \mathrm{A} / \mathrm{mm}^{2}\right)$ \\
\hline 1.4 & 15.5 & 38.7 & 23.1 \\
\hline 1.6 & 24.0 & 38.3 & 14.4 \\
\hline 1.8 & 36.1 & 38.3 & 2.2 \\
\hline 2.0 & 37.1 & 38.2 & 1.1 \\
\hline 2.2 & 36.6 & 37.4 & 0.9 \\
\hline 2.4 & 36.3 & 36.9 & 0.6 \\
\hline
\end{tabular}

Table 3. Current densities for dependence on the hole diameter of the accelerator grid $\left(d_{\mathrm{sc}}=3.4 \mathrm{~mm}\right)$.

\begin{tabular}{|c|c|c|c|}
\hline$d_{\mathrm{ac}}(\mathrm{mm})$ & $i_{\mathrm{b}}\left(\mu \mathrm{A} / \mathrm{mm}^{2}\right)$ & $i_{\mathrm{sc}}\left(\mu \mathrm{A} / \mathrm{mm}^{2}\right)$ & $i_{\mathrm{ac}}\left(\mu \mathrm{A} / \mathrm{mm}^{2}\right)$ \\
\hline 1.8 & 25.1 & 38.3 & 13.2 \\
\hline 2.0 & 36.0 & 37.9 & 1.9 \\
\hline 2.2 & 36.5 & 37.6 & 1.1 \\
\hline 2.4 & 36.2 & 37.1 & 0.9 \\
\hline
\end{tabular}

(a) Ion density $n_{\mathrm{i}}, \mathrm{m}^{-3}$

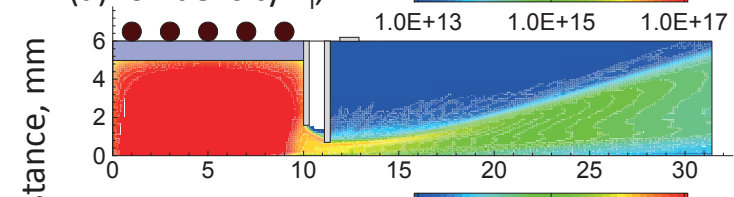

$\frac{\pi}{0}(b)$

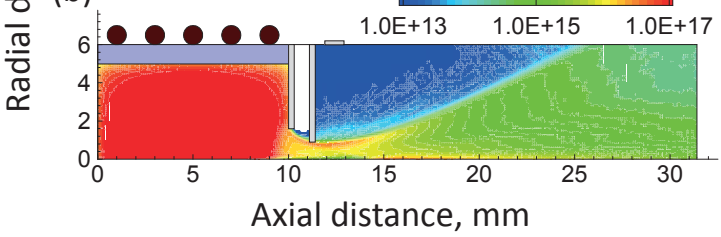

Fig. 8. Distributions of ion density for (a) $d_{\mathrm{ac}}=1.4 \mathrm{~mm}$, (b) $d_{\mathrm{ac}}=$ $1.8 \mathrm{~mm}$ at $d_{\mathrm{sc}}=3.2 \mathrm{~mm}$. 


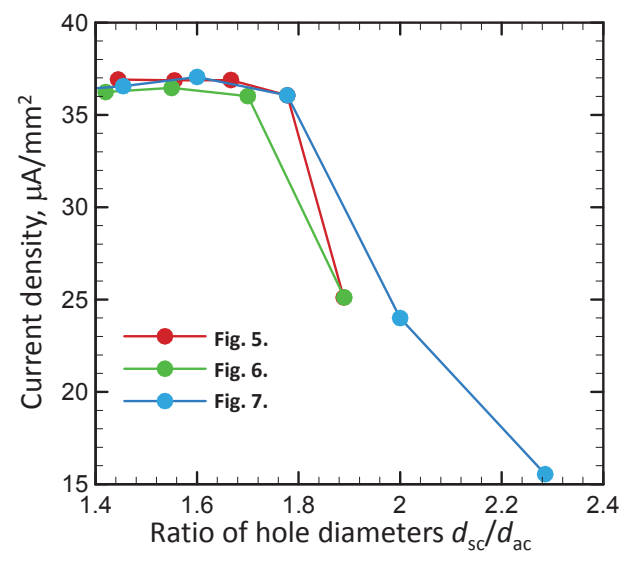

Fig. 9. Dependence on the ratio of the hole diameters.

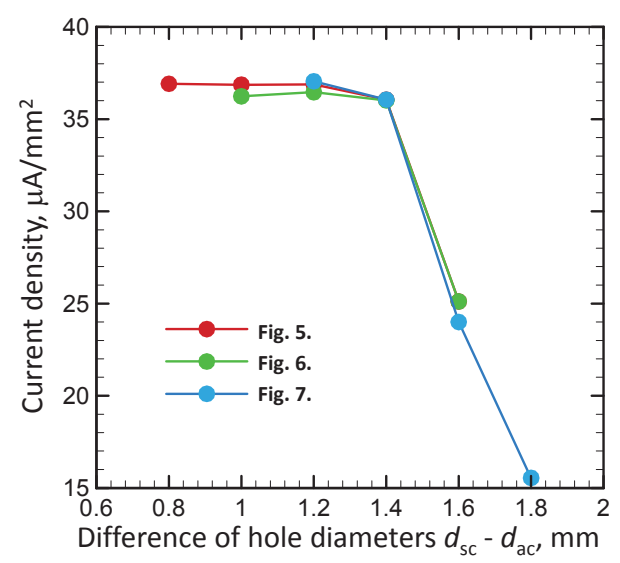

Fig. 10. Dependence on the difference of the hole diameters.

Fig. 8 (a) directly collides with the accelerator grid. Then, to find the relation between the diameters of screen and accelerator grids hole, we have investigated the ratio and the difference of hole diameters to the current density as shown in Figs. 9 and 10. It can be said that the difference between hole diameters is one of the useful parameters for ion beam extraction.

As described previously, the ion beam current depends on the gap distance $l$ between the screen and accelerator grids and the thickness of the screen grid $t_{\mathrm{sc}}$, so that we have also investigated the dependence on the hole diameters difference with variations of the gap distance and the thickness of the screen grid. The results are shown in Figs. 11 and 12, where the former is fixed at $t_{\mathrm{sc}}=0.3 \mathrm{~mm}$ and the latter is at $l=0.8$ $\mathrm{mm}$. The other conditions are as follows: $p=3.2 \mathrm{mTorr}, P_{\mathrm{abs}}=$ $500 \mathrm{~mW}, V_{0}=1100 \mathrm{~V}$, and $t_{\mathrm{ac}}=0.3 \mathrm{~mm}$. As shown in Fig. 11, the turning point is $1.4 \mathrm{~mm}$ if the gap distance between the grids is smaller than $0.8 \mathrm{~mm}$. In Fig. 12, likewise, the turning point is also $1.4 \mathrm{~mm}$ if the screen grid thickness is smaller than $0.5 \mathrm{~mm}$. For ion thrusters, it is desirable to increase the hole diameter of screen grid and to reduce that of accelerator grid, so that the optimum value of the difference between the hole diameters of screen and accelerator grid is $1.4 \mathrm{~mm}$. Moreover, it is better to reduce both the gap distance between

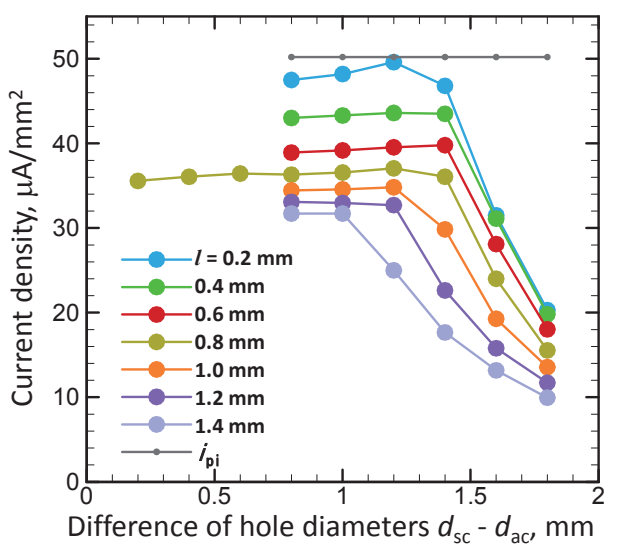

Fig. 11. Dependence on the difference of the hole diameters in various $l\left(t_{\mathrm{sc}}=0.3 \mathrm{~mm}\right)$.

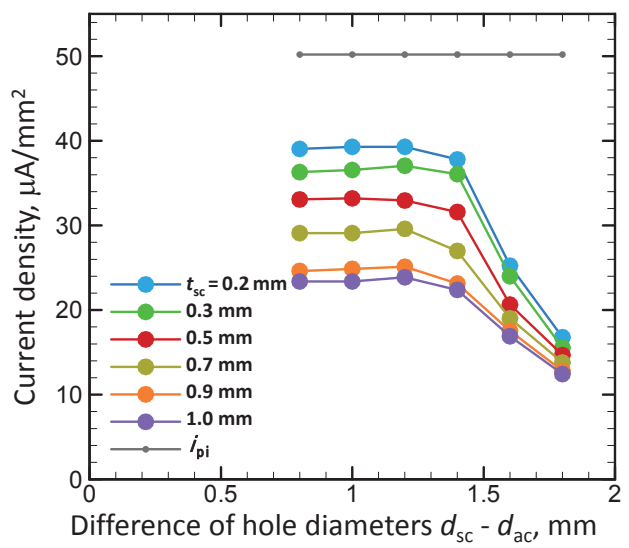

Fig. 12. Dependence on the difference of the hole diameters in various $t_{s c}(l=0.8 \mathrm{~mm})$.

(a) Ion density $n_{\mathrm{i}}, \mathrm{m}^{-3}$

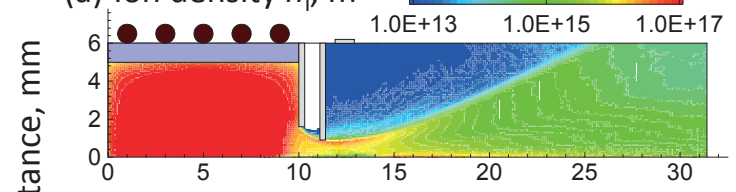

(b)

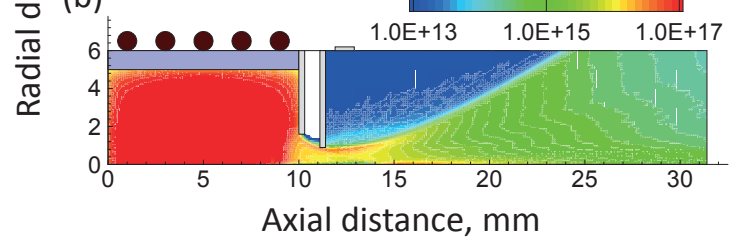

Fig. 13. Distributions of ion density for (a) with neutralization and (b) without neutralization. 
Table 4. Current densities under the optimum condition with and without neutralization.

\begin{tabular}{|c|c|c|c|}
\hline & $i_{\mathrm{b}}\left(\mu \mathrm{A} / \mathrm{mm}^{2}\right)$ & $i_{\mathrm{sc}}\left(\mu \mathrm{A} / \mathrm{mm}^{2}\right)$ & $i_{\mathrm{ac}}\left(\mu \mathrm{A} / \mathrm{mm}^{2}\right)$ \\
\hline $\begin{array}{c}\text { with } \\
\text { neutralization }\end{array}$ & 36.0 & 38.2 & 2.2 \\
\hline $\begin{array}{c}\text { w/o } \\
\text { neutralization }\end{array}$ & 36.0 & 38.2 & 2.2 \\
\hline
\end{tabular}

the grids and the thickness of the screen grid as small as possible to obtain higher thrust density, where the upper limit of $i_{\mathrm{b}}$ is $i_{\mathrm{p}}$.

\subsection{Effect of electron injection}

Finally, since we focus on the ion beam current densities and beam profiles near the thruster exit in this study, the interaction between the ion beam and electrons for neutralization has to be discussed, where we neglect the interaction between the ion beam and background plasma assuming its effect near the thruster is much smaller than that of electrons ejected from a neutralizer. We have calculated the ion beam extraction with and without electron injection for neutralization, where electrons are injected at $z=20-30 \mathrm{~mm}$ with a Maxwellian velocity distribution at an electron temperature of $2 \mathrm{eV}$. Figure 13 shows the distributions of ion density under the optimum condition: $p=3.2 \mathrm{mTorr}, P_{\mathrm{abs}}=$ $500 \mathrm{~mW}, V_{0}=1100 \mathrm{~V}\left(V_{\mathrm{sc}}=1000 \mathrm{~V}\right.$ and $\left.V_{\mathrm{ac}}=-100 \mathrm{~V}\right), l=$ $0.8 \mathrm{~mm}, t_{\mathrm{sc}}=0.3 \mathrm{~mm}, t_{\mathrm{ac}}=0.3 \mathrm{~mm}, d_{\mathrm{sc}}=3.2 \mathrm{~mm}$, and $d_{\mathrm{ac}}=1.8$ $\mathrm{mm}$, and the current densities are summarized in Table 4. It is clear that electrons for neutralization do not affect the beam current density or the ion beam profile. Since the calculation area for beam extraction is relatively small, the next steps include expanding the vacuum region in Fig. 1.

\section{Conclusions}

In this study, we have investigated the ion beam extraction mechanism by using PIC/MCC simulations under various conditions of grid structures. As a result, in relation to the previous effective gap distance between the grids, we have found that the ion beam current is affected by the gap distance of the grids and thickness of the screen grid, but is not affected by the hole diameter of the screen grid. In addition, we have also found that the optimum value of the difference between the hole diameter of the screen grid and that of the accelerator grid is $1.4 \mathrm{~mm}$ at an absorbed power of $500 \mathrm{~mW}$, and that it is better to reduce both the gap distance between the grids and the thickness of the screen grid as small as possible to obtain higher thrust density. In future work, we will calculate under more various conditions, and conduct experiments based on these results to examine the validity.

\section{Acknowledgments}

This work was financially supported in part by Casio Science Promotion Foundation, the Sumitomo Foundation, and the Foundation for the Promotion of Ion Engineering. The computer simulation was performed on the KDK computer system at Research Institute for Sustainable Humanosphere, Kyoto University.

\section{References}

1) Micci, M. M. and Ketsdever, A. D.: Micropropulsion for Small Spacecraft, American Institute of Aeronautics and Astronautics, Reston, 2000

2) Koizumi, H., Komurasaki, K., Aoyama, J. and Yamaguchi, K. Engineering Model of the Minature Ion Propulsion System for the Nano-satellite: HODOYOSHI-4, Trans. JSASS Aerospace Tech. Japan, 12 (2014), pp. Tb_19-Tb_24.

3) Patterson, M. J., Haag, T. W., Foster, J. E., Young, J. A. and Crofton M. W.: Development Status of High-Thrust Density Electrostatic Engines, Proceedings of the 50th AIAA/ASME/SAE/ASEE Joint Propulsion Conference, Cleveland, Ohio, USA, 2014, AIAA-2014-3422.

4) Patterson, M. J., Herman, D., Shastry, R., Van Noord, J. and Foster, J. E.: Annular-Geometry Ion Engine: Concept, Development Status, and Preliminary Performance, Proceedings of the 48th AIAA/ASME/SAE/ASEE Joint Propulsion Conference \& Exhibit, Atlanta, Georgia, USA, 2012, AIAA-2012-3798.

5) Takao, Y., Sakamoto, M., Eriguchi, K. and Ono, K.: Investigation of Plasma Characteristics and Ion Beam Extraction for a Micro RF Ion Thruster, Trans. JSASS Aerospace Tech. Japan, 12 (2014), pp. $\mathrm{Pb} 13-\mathrm{Pb} 18$.

6) Hayashi, M.: Determination of Electron-Xenon Total Excitation Cross-Sections, from Threshold to $100 \mathrm{eV}$, from Experimental Values of Townsend's a, J. Phys. D, 16 (1983), pp. 581-589.

7) Heer, F. J. d., Jansen, R. H. J. and Kaay, W. v. d.: Total Cross Sections for Electron Scattering by $\mathrm{Ne}, \mathrm{Ar}, \mathrm{Kr}$ and Xe, J. Phys. B, 12 (1979), pp. 979-1002.

8) Rapp, D. and Englander-Golden, P.: Total Cross Sections for Ionization and Attachment in Gases by Electron Impact. I. Positive Ionization, J. Chem. Phys., 43 (1965), pp. 1464-1479.

9) Boyd, I. D.: Modeling of the Near Field Plume of a Hall Thruster, J. Appl. Phys., 95 (2004), pp. 4575-4584.

10) Birdsall, C. K. and Langdon, A. B.: Plasma Physics via Computer Simulation, IOP Publishing, Bristol, U. K., 1991.

11) Vahedi, V. and Surendra, M.: A Monte Carlo Collision Model for the Particle-in-Cell Method: Applications to Argon and Oxygen Discharges, Comput. Phys. Commn., 87 (1995), pp. 179-198.

12) Veboncoeur, J. P.: Symmetric Spline Weighting for Charge and Current Density in Particle Simulation, J. Comput. Phys., 174 (2001), pp. 421-427.

13) Veboncoeur, J. P.: Particle Simulation of Plasmas: Review and Advances, Plasma Phys. Control. Fusion, 47 (2005), pp. A231A260.

14) Takao, Y., Kusaba, N., Eriguchi, K. and Ono, K.: Two-dimensional Particle-in-Cell Monte Carlo Simulation of a Miniature Inductively Coupled Plasma Source, J. Appl. Phys., 108 (2010), pp. 093309$1 \sim 8$.

15) Funaki, I., Kuninaka, H., Toki, K., Simizu, Y. and Nishiyama, K.: Verification Test of Carbon-Carbon Composite Grids for Microwave Discharge Ion Thruster, J. Propul. Power, 18 (2002), pp. 169-175. 